\title{
Pendampingan Peningkatan Kualitas Keripik Pisang Muli Vacum Dengan Perbaikan Proses, Pengemasan Dan Lebaling Di Pekon Pakunegara Pesisir Barat
}

\author{
Septa Riadi ${ }^{1}$, Deviana $\operatorname{Sari}^{1}$, Husna Purnama ${ }^{1}$, Maristiana Ayu ${ }^{1}$ \\ Universitas Sang Bumi Ruwa Jurai \\ septa.riadi.sr@gmail.com,devianasari.18@gmail.com, husnapurnama@gmail.com,maristiana2017@gmail.com
}

\begin{abstract}
Abstrak
Sebelum tahun 1970, Pekon Paku Negara terdiri dari satuan pemukiman, antara lain: Talang Kejadian, Ulok Magiwong, Cukuh Sinuman, Simpor, Atar Puding, Usang Pring dan Usang Madat. Pada 1972, talang tersebut menjadi Pemangku Paku Negara yang masuk dalam wilayah administratif dari Pekon Biha. Potensi desa Pakunegara sangat besar yang dihasilkan dari beberapa sektor sawah dan perkebunan yakni berupa padi dan pisang serta buah-buahan lainnya. Potensi hasil perkebunan itu ingin dimanfaatkan oleh Kopearsi Simpan Usaha Tratai Indah untuk membuat produk olahan makanan yang berbahan baku buah-buahan terutama pisang yang dapat dijual ditingkat lokal yaitu dalam desa Pakunegara dan desa tetangga. Namun dalam pengelolaan sumber daya yang ada masih terbatas, dalam hal ini mandapati berbagai permasalahan seperti masyarakat dan KSU tidak tahu proses pembuatan keripik pisang melalui proses yang baik atau tidak baik dari kualitas bahan baku maupun proses produksi dan Masyarakat dan KSU tidak tau bagaimana memasarkan produknya agar menarik dan masih menggunakan Teknik pemasaran tradisional. Kegiatan pengabdian berjalan lancar, dihadiri oleh 5 anggota KSU yang sangat antusias dengan kegiatan pendampingan dan masyarakat sekitar turut membantu jalannya kegiatan. Tim pengabdian berhasil meningkatkan kemampuan dan pemahaman terkait pembuatan keripik pisang muli vacuum, pengemasan serta labeling menggunakan cara yang lebih modern. Hal tersebut ditunjukkan perbedaan hasil pretest dan postest yang bertujuan untuk mengetahui dan mengevaluasi tingkat pemahaman peserta. Dengan pengetahuan dan kemampuan yang sudah diperoleh dari kegiatan pendampingan, diharapkan anggota KSU mampu menjadi penggerak bagi masyarakat sekitar untuk meningkatkan perekonomian di Pekon Pakunegara.
\end{abstract}

Kata Kunci : Pisang Muli Vacum, Pengemasan, Labeling

\begin{abstract}
Prior to 1970, Pekon Paku Negara consisted of residential units, including: Talang Genesis, Ulok Magiwong, Cukuh Sinuman, Simpor, Atar Puding, Usang Pring and Usang Madat. In 1972, the gutter became Stakeholder Paku Negara which was included in the administrative area of Pekon Biha. The potential of Pakunegara village is very large resulting from several sectors of rice fields and plantations in the form of rice and bananas and other fruits. The potential of this plantation product is intended to be used by Kopearsi Simpan Usaha Tratai Indah to make processed food products made from raw fruits, especially bananas that can be sold at the local level, namely in Pakunegara village and neighboring villages. However, in the management of existing resources, it is still limited, in this case there are various problems such as the community and KSU not knowing the process of making banana chips through a good or bad process from the quality of raw materials and production processes and the community and KSU do not know how to market their products so that interesting and still using traditional marketing techniques. The service activities went smoothly, attended by 5 KSU members who were very enthusiastic about the mentoring activities and the surrounding community helped run the activities. The service team succeeded in increasing their ability and understanding regarding the manufacture of muli vacuum banana chips, packaging and labeling using more modern methods. This is indicated by the difference in the results of the pretest and posttest which aims to determine and evaluate the level of understanding of the participants. With the knowledge and abilities that have been obtained from mentoring activities, it is hoped that KSU members will be able to become a driving force for the surrounding community to improve the economy in Pekon Pakunegara.
\end{abstract}

Keywords: Muli Vacum Banana, Packaging, Labeling 


\section{PENDAHULUAN}

Kelembagaan sosial sebagai wadah dan juga alat untuk memfasilitasi kegiatan-kegiatan yang ada di masyarakat Paku negara ini meliputi kelembagaan formal dan informal. Kelembagaan formal terdiri dari lembaga pemerintahan seperti Pemerintahan Pekon, Lembaga Himpun Pemekonan (LHP), dan Lembaga Kemasyarakatan Pekon yang meliputi kelompok PKK, Pemangku, Posyandu, Kelompok Tani, Keluarga Berencana (KB), dan Posyandu. Identifikasi kelembagaan di Pekon Paku negara. Selain sejumlah kelembagaan formal bentukan pekon Pakunegara sebagaimana dikemukakan di atas, terdapat kelembagaan formal yang dibentuk oleh masyarakat seperti kelompok tani, Kelompok Simpan Usaha (KSU) Teratai Indah dan masih banyak kelompok lainnya yang di inisiasi oleh beberapa lembaga.

Terkait kelembagaan sosial yang dibuat guna menampung semua aktivitas-aktivitas warga, pekon Pakunegara memiliki Kelompok Simpan Usaha (KSU) Teratai Indah yang merupakan sekelompok orang yang bersepakat untuk saling membantu dan bekerja sama membangun sumber pelayanan ekonomi dan sosial guna menumbuh kembangkan usaha yang ramah lingkungan dan meningkatkan taraf hidup para anggota dan keluarganya. KSU ini dipilih karena diharapkan bisa mengajak masyarakat belajar untuk berkelompok mengadakan simpanan serta membentuk unitunit usaha agar masyarakat bisa berkembang. Kelompok Simpan Usaha "Teratai Indah" merupakan kelompok simpan usaha yang beranggotakan perempuan yang ada di pekon Paku Negara, Kecamatan Pesisir Selatan, Kabupaten Pesisir Barat. Kelompok ini berdiri untuk menjadi salah satu lembaga yang dapat menunjang kemudahan dana skala mikro, mengajarkan budaya menabung dan meningkatkan perekonomian dengan membuat unit-unit usaha dengan memanfaatkan Sumbar Daya Alam (SDA) dan Sumber Daya Manusia (SDM). KSU Teratai Indah berdiri pada tanggal 14 November 2018 dengan anggota pendiri 23 orang, hingga sekarang beranggotakan 58 orang.

Potensi desa Pakunegara sangat besar yang dihasilkan dari beberapa sektor sawah dan perkebunan yakni berupa padi dan pisang serta buah-buahan lainnya. Potensi hasil perkebunan itu ingin dimanfaatkan oleh Kopearsi Simpan Usaha Tratai Indah untuk membuat produk olahan makanan yang berbahan baku buah-buahan terutama pisang yang dapat dijual ditingkat lokal yaitu dalam desa Pakunegara dan desa tetangga.

Tim Pengabdian dari Universitas Sang Bumi Ruwa Jurai mendapati permasalahan utama terkait pengelolaan Keripik yaitu Masyarakat dan KSU tidak tahu proses pembuatan keripik pisang melalui proses yang baik atau tidak baik dari kualitas bahan baku maupun proses produksi, dan masyarakat dan KSU tidak tau bagaimana memasarkan produknya agar menarik dan masih menggunakan Teknik pemasaran tradisional.

\section{METODE PELAKSANAAN}

Metode pelaksanaan pengabdian terdiri empat tahapan yaitu survey dan studi, sosialisasi, pelatihan kepada anggota KSU, dan kegiatan pendampingan proses vacum, mengemas serta labeling. Penjelasan dari masing-masing tahapan sebagai berikut: 1) Survey dan studi 2) Sosialisasi dan Lokakarya kegiatan 3) Pelatihan kepada anggota KSU 4) Kegiatan pendampingan proses vacuum, mengemas dan labeling. 
Sruvey dan Studi digunakan untuk tahap persiapan, survey dilakukan untuk mengetahui situasi terkait dengan permasalahan yang di hadapi oleh KSU Teratai Indah Pakunegara, dan diharapkan dapat di jadikan acuan dalam pelaksanaan pengabdian.

Sosialisasi dipilih untuk menyampaikan konsep-konsep yang penting untuk dimengerti dan dikuasai oleh masyarakat. Penggunaan metode ini dengan pertimbangan bahwa metode ceramah yang dikombinasikan dengan gambar-gambar dan display mengenai produk yang menarik dan memberikan materi terkait dengan teknik penjualan yang efektive dan efisien.

Pelatiha kepada anggota KSU dipilih untuk menunjukkan suatu proses pembuatan produk dengan vacum, setelah itu mendemonstrasikan kemasakan produk agar lebih menarik seperti besek dan paper bag yang warna warni, serta mendemonstrasikan memberi label pada produk agar harga jual menjadi lebih tinggi.

Setelah pelatihan akan ada tindak lanjut terkait pelaksanaanya selama 1 hari, dan akan mendapingi anggota KSU serta masyarakat dalam membuat produk yang baik, memberi kemasan dan label pada produk. Diharapkan dalam tahap ini, masyarakat sudah mampu mengimplementasikan semua prosesnya.

Sasaran kegiatan program pengabdian masyarakat melalui metode pendampingan yang akan diselenggarakan Fakultas Ekonomi Universitas Sang Bumi Ruwa Jurai adalah anggota KSU Teratai indah Pakunegara dan masyarakat pekon Pakunegara yang berkontribusi dalam pembuatan kripik pisang.

\section{HASIL DAN PEMBAHASAN}

Pendampingan pembuatan kripik pisang muli vacuum, pengemasan dan labeling di KSU Teratai indah Pakunegara dilaksanakan 18-20 Oktober 2021 di balai desa. Kegiatan ini di hadiri oleh anggota KSU sebanyak 6 orang, sekertaris desa dan beberapa masyarakat Pakunegara

Kegiatan Pendampingan pembuatan keripik pisang vacuum, pengemasan dan labeling di Pekon Pakunegara yang dilakukan Tim Pengabdian dari Fakultas Ekonomi Universitas Sang Bumi Ruwa Jurai berjalan dengan lancar. Kegiatan tersebut di laksanakan selama 3 hari, dimulai hari pertama dengan pemaparan materi pembuatan keripik pisang muli dengan perbaikan menggunakan vacuum, materi terkait dengan pengemasan serta materi terkait labeling yang harus memenuhi standar labeling. Sebelum pemamaparan materi, peserta yang berjumlah 6 orang anggota KSU diberikan pretest yang bertujuan untuk mengetahui tingkat pemahaman para peserta topik pengabdian terutama terkait membuat produk agar menarik untuk dijual. Pretest dilakukan dengan mengisi lembar pertanyaan. Berikut hasil pretest yang sudah dilakukan oleh tim pengabdian:

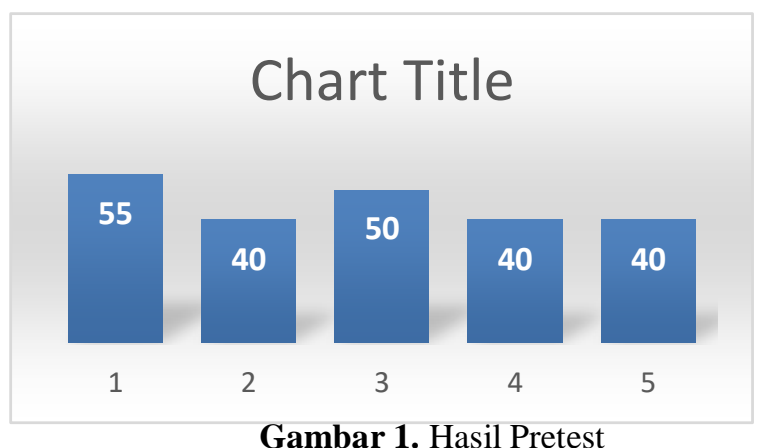

Gambar 1. Hasil Pretest 
Dapat dari grafik di atas bahwa dari 5 anggota KSU 1 orang memperoleh nilai 55, 1 orang memperoleh nilai 50 dan 3 orang memperoleh nilai 40. Artinya masih sangat kurang pemahaman terkait proses, pengemasan dan labeling untuk membuat keripik pisang lebih menarik. Setelah pretest, tim pengabdian memberikan materi dan peserta sangat antusia dengan materi yang diberikan karena terjadi diskusi yang sangat mendalam terkait materi. Peserta bertanya dan membagikan pengelaman-pengelaman terkait pembuatan kripik pisang yang masih manual dan belum dikemas sesuai standar.

Hari kedua, tim pengabdian mulai melaksanakan pendampingan pembuatan keripik pisang muli vacuum. Dimulai dari persiapan, proses pembuatan kripik sampai dengan ekstraksi keripik pisang muli.

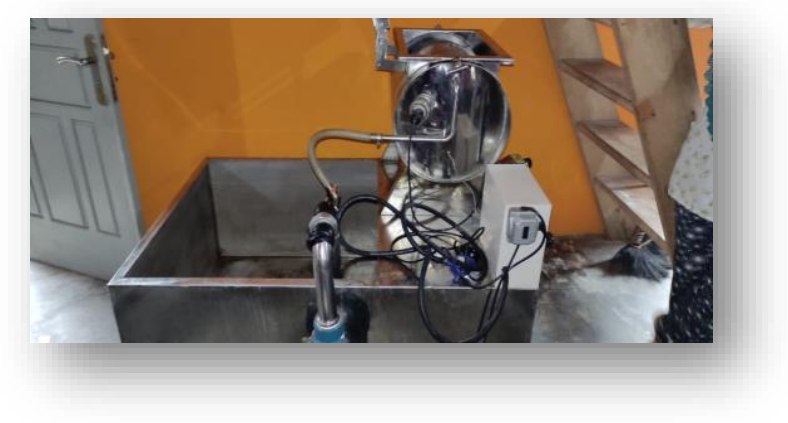

Gambar 2. Mesin Vaccum

Hari ketiga. Tim Pengabdian melaksakan pendampingan untuk pengemasan dan labeling. Peserta melakukan penimbangan pisang goreng hasil vacuum sebanyak 100 gram, memasukkan kedalam plastic klip. Lalu peserta menutup klip dengan sempurna sesuai intruksi yang diberikan oleh tim pengabdian. memasukkan hasil pisang yang sudah di packing oleh plastik klip, lalu dimaskkan kedalam besek bambu. Ikat besek bamboo dengan tali rame lalu beri label yang memenuhi persyaratan labeling yang sudah dibuatkan oleh tim pengabdian sebagai contoh.

Setelah mengikuti semua tahapan pendampingan dari hari pertama sampai ketiga. Peserta diberikan post test untuk mengevaluasi tingkat pemahaman peserta mengikuti kegiatan pendampingan. Post test dilakuakan dilakuan dengan menggunakan pertanyaan dan peserta akan mengisi lalu akan diberikan nilai. Dan nilai tersebut akan menjadi alat ukur tingkat pemahaman peserta selama mengikuti pendampingan. Hasil post test dapat dilihat dari grafik 2 di bawah ini:

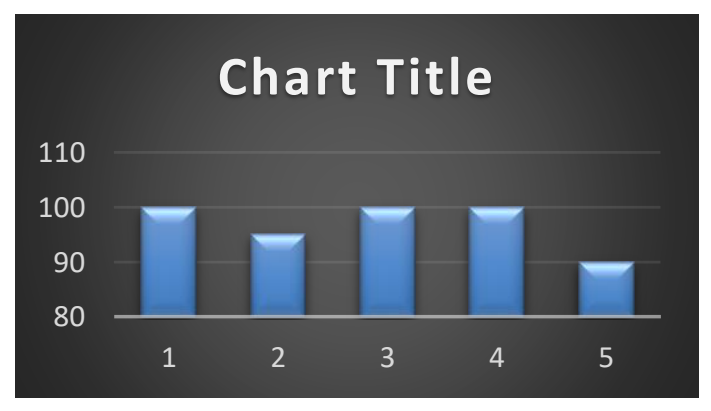

Grafik 2. Hasil Post Test Peserta

Dari grafik diatas dapat di lihat bahwa dari 5 peserta anggota KSU, 1 peserta memperoleh nilai 90, 1 Peserta memperoleh nilai 95 dan 3 peserta memperoleh nilai 100. Nilai rata-rata post test mengenai pendampingan adalah 97. Dan nilai ini jauh lebih besar dibandingan nilai pre test yang dilakukan sebelum adanya pendampingan. Hal ini menunjukkan peningkatan secara 
signifika pemahaman dan kemampuan anggota KSU dalam mengelola keripik pisang muli dengan cara yang lebih modern yaitu menggunakan vaccum, kemampuan dalam mengemas keripik dan yang paling penting membuat keripik menjadi menarik dengan metode labeling yang sesuai persyaratan dan kekinian.

\section{KESIMPULAN}

Simpulan dari kegiatan pengabdian kepada masyarakat yang di laksanakan oleh tim pengabdian dari Fakultas Ekonomi Universitas Sang Bumi Ruwa Jurai yaitu: kegiatan pengabdian berjalan lancar, dihadiri oleh 5 anggota KSU yang sangat antusias dengan kegiatan pendampingan dan masyarakat sekitar turut membantu jalannya kegiatan. Tim pengabdian berhasil meningkatkan kemampuan dan pemahaman terkait pembuatan keripik pisang muli vacuum, pengemasan serta labeling menggunakan cara yang lebih modern. Dengan pengetahuan dan kemampuan yang sudah diperoleh dari kegiatan pendampingan, diharapkan anggota KSU mampu menjadi penggerak bagi masyarakat sekitar untuk meningkatkan perekonomian di Pekon Pakunegara.

\section{Saran}

Saran yang dapat diberikan untuk pengabdian selanjutnya adalah penyuluhan dan pendampingan dalam memasarkan keripik pisang muli dengan menggunakan $e$-commerce yang dapat membantu masyarakat memasarkan produk keripiknya berbasis digital agar mendapatkan jangkauan yang lebih luas.

\section{UCAPAN TERIMA KASIH}

Puji syukur penulis panjatkan kehadiran Allah SWT, atas karunia yang dilimpahkan, sehingga pelaksanaan pengabdian kepada masyarakat yang berjudul "Pendampingan Peningkatan Kualitas Keripik Pisang Muli Vacum Dengan Perbaikan Proses, Pengemasan Dan Lebaling Di Pekon Pakunegara Pesisir Barat" dapat terlaksana dengan baik dan lancar. Terselenggaranya kegiatan pengabdian kepada masyarakat ini berkat kerjasama dan dukungan berbagai pihak, sehingga sudah sepatutnya kami menyampaikan ucapan terimakasih kepada: Dekan Fakultas Ekonomi, yang telah memberikan izin kepada tim pengabdian Fakultas Ekonomi dalam melaksanakan kegiatan pengabdian kepada masyarakat, Pekon Pakunegara Pesisir Barat yang telah memberikan kami kesempatan untuk melaksanakan kegiatan pengabdian di Pekon Pakunegara, Rekan-rekan tim dosen dan mahasiswa Fakultas Ekonomi sebagai pelaksana kegiatan pengabdian kepada masyarakat di lapangan yang telah melaksanakan kegiatan ini dengan baik.

\section{DAFTAR PUSTAKA}

Antarlina, S.S. dan Y. Rina. 2005. Pengolahan keripik buah-buahan lokal Kalimantan menggunakan penggoreng vakum. hlm. 1113-1126. Dalam J. Munarso, S. Prabawati, Abubakar, Setyajit. Risfaheri, F. Kusnandar, dan F. Suaib (Ed.). Prosiding Seminar Nasional Teknologi Inovatif Pascapanen untuk Pengembangan Industri Berbasis Pertanian. Buku II: Alsin, Sosek dan Kebijakan, 7-8 September 2005. Balai Besar Penelitian dan Pengembangan Pascapanen Pertanian dan Fakultas Teknologi Pertanian IPB, Bogor. 
Angipora, Marinus. P. 2002. Dasar-Dasar Pemasaran. Edisi Revisi. Cetakan Kedua. Raja Grafindo, Jakarta.

Angipora, Marinus. P. 2002. Dasar-Dasar Pemasaran. Edisi Revisi. Cetakan Kedua. Raja Grafindo, Jakarta.

Basu Swastha dan Irawan, 2005, Asas-asas Marketing, Liberty, Yogyakarta

Djaslim, Saladin. (2003). Manajemen Pemasaran Analisis, Perencanaan, Pelaksanaan, dan Pengendalian. Bandung: Linda Karya

Fandy Tjiptono, 1997, Strategi Pemasaran, Edisi 1, Penerbit Andi, Yogyakarta

J. Setiadi, Nugroho, SE., MM., 2003, "Perilaku Konsumen Konsep dan Implikasi untuk Strategi dan Penelitian Pemasaran". Jakarta: Kencana.

Kotler, Philip (2000). Prinsip - Prinsip Pemasaran Manajemen, Jakarta : Prenhalindo.

Philip Kotler, 2005, Manajemen Pemasaran : Analisis, Perencanaa dan Implementasi dan Kontrol, Jilid I, Erlangga, Jakarta.

Swastha, Basu. 1984. Azas-Azas Marketing. Yogyakarta: Liberty. 